\title{
The role of interconnected hub neurons in cortical dynamics
}

\author{
Hesam Setareh", Moritz Deger, Wulfram Gerstner \\ From The Twenty Third Annual Computational Neuroscience Meeting: CNS*2014 \\ Québec City, Canada. 26-31 July 2014
}

The structure of synaptic connectivity plays an important role in information processing and dynamics of neuronal microcircuits. Previous work has shown that cortical microcircuits contain non-random features of the network structure [1], and that these affect neuronal dynamics [2]. Earlier models of non-random network structure proposed local correlations in synaptic weight or connection number (degree) [3,4]. In such network models, there are neurons receiving stronger synaptic weights or higher numbers of synapses compared to other neurons. Here, we refer to the former neuron type as hub neuron, or simply hub. In other words, a hub

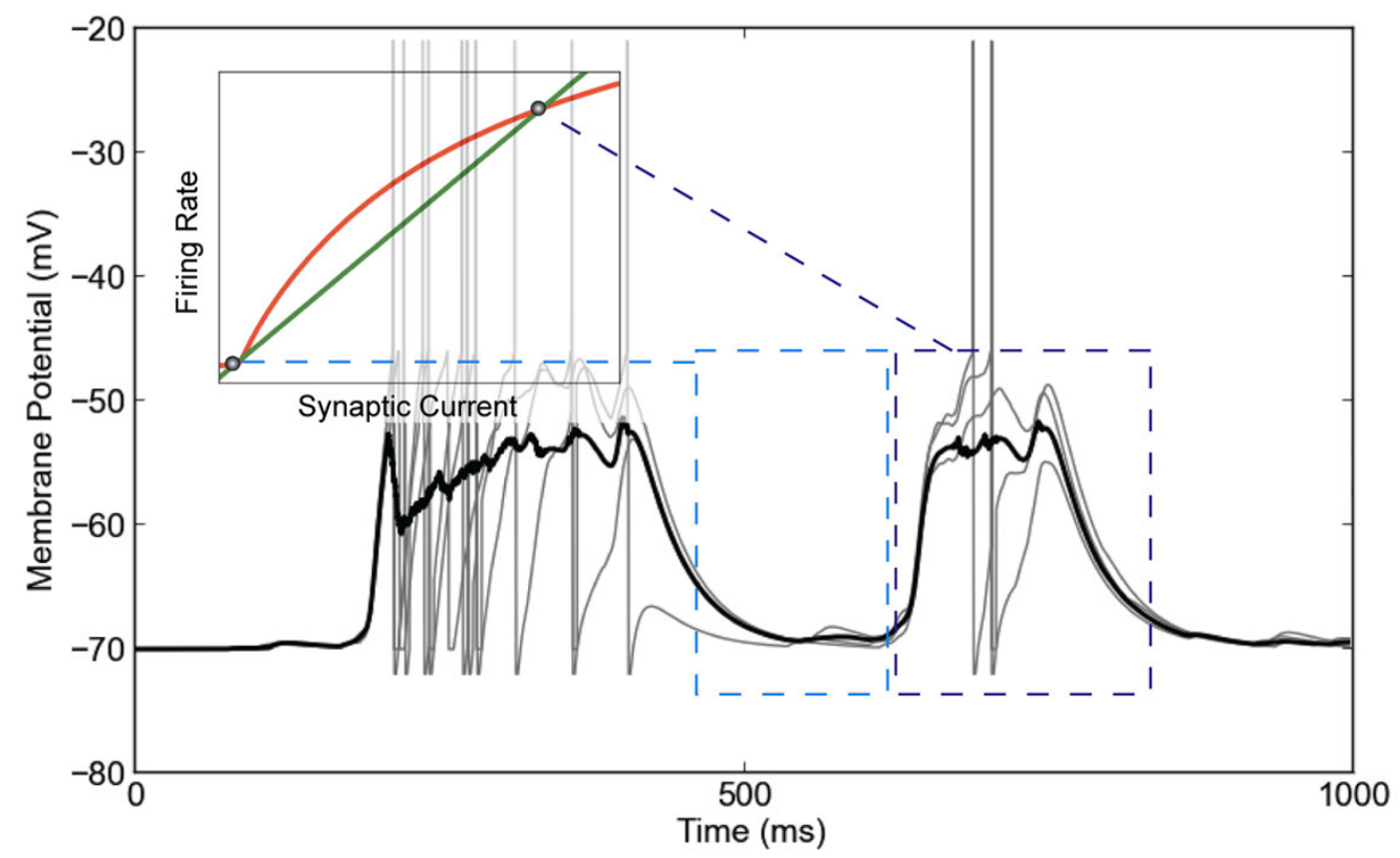

Figure 1 Neuronal populations with connected hubs show up/down state oscillations (simulation). Membrane potential of individual neurons (gray) and average over all neurons (black). Inset indicates self-consistent rate analysis. The two rate fixed points are associated with the up and down states.

\footnotetext{
* Correspondence: hesam.setareh@epfl.ch

School of Life Sciences, Brain Mind Institute and School of Computer and

Communication Sciences, École polytechnique fédérale de Lausanne, 1015
}

Lausanne EPFL, Switzerland 
receives strong synapses, but not necessarily a higher number of synapses. Importantly, a hub results from the structure of the network and not from differences in neuron parameters. Here we introduce the network feature of connectedness of hub neurons. We show that an elevated connection probability between hubs affects various aspects of network activity, ranging from spontaneous oscillations to the response of cortical populations to stimulation.

A subpopulation of connected hubs can be analyzed using common mean-field methods. This analysis reveals two stable fixed points of the spiking activity, one at a low firing rate and another one at a high firing rate.

We first model a single layer of a column of rodent barrel cortex. The subpopulation of connected hubs switches between the two fixed points and generates upstate/down-state oscillations (see Figure 1), and thus acts as the "heart" of the oscillator. Furthermore, we demonstrate that the different characteristics of cortical layer responses in optogenetic stimulation experiments [5] can be explained by the absence or presence of connected hubs. Finally, we extend the system to contain several connected hubs subpopulations. Such multiheart oscillators generate irregular oscillations, reminiscent of spontaneous cortical activity.

\section{Acknowledgements}

Research was supported by the European Research Council (grant agreement no. 268 689, H.S.), the European Community's Seventh Framework Program (Grant Agreement no. 269921, BrainScaleS, H.S and M.D.) and the Swiss National Science Foundation (grant agreement no. 200020_147200, M.D.).

Published: 21 July 2014

\section{References}

1. Song S, Sjöström PJ, Reigl M, Nelson S, Chklovskii DB: Highly nonrandom features of synaptic connectivity in local cortical circuits. PLoS Biology 2005, 3(3):e68

2. Pernice $V$, Deger $M$, Cardanobile $S$, Rotter $S$ : The relevance of network micro-structure for neural dynamics. Front Comput Neurosci 2013, 7(72).

3. Koulakov AA, Hromádka T, Zador AM: Correlated connectivity and the distribution of firing rates in the neocortex. J Neurosci 2009 29(12):3685-3694.

4. Roxin A: The role of degree distribution in shaping the dynamics in networks of sparsely connected spiking neurons. Front Comput Neurosci 2011, 5(8)

5. Beltramo $\mathrm{R}$, et al: Layer-specific excitatory circuits differentially control recurrent network dynamics in the neocortex. Nat Neurosci 2013, 16:227-234.

doi:10.1186/1471-2202-15-S1-P158

Cite this article as: Setareh et al:: The role of interconnected hub neurons in cortical dynamics. BMC Neuroscience 2014 15(Suppl 1):P158.

\section{Submit your next manuscript to BioMed Central} and take full advantage of:

- Convenient online submission

- Thorough peer review

- No space constraints or color figure charges

- Immediate publication on acceptance

- Inclusion in PubMed, CAS, Scopus and Google Scholar

- Research which is freely available for redistribution

Submit your manuscript at www.biomedcentral.com/submit 